\title{
Production Innovation and Effective Dissemination of Information for Operator 4.0
}

\author{
Dan LI ${ }^{\mathrm{a}, 1}$, Åsa FAST-BERGLUND ${ }^{\mathrm{a}}$ and Dan PAULIN ${ }^{\mathrm{b}}$ \\ ${ }^{a}$ Chalmers University of Technology, Department of Industrial and Materials Science \\ ${ }^{\mathrm{b}}$ Chalmers University of Technology, Department of Technology Management and \\ Economics
}

\begin{abstract}
The manufacturing industry is becoming increasingly more complex as the paradigm of mass-production moves, via mass-customization, towards personalized production and Industry 4.0. This increased complexity in the production system also makes everyday work for shop-floor operators more complex. To take advantage of this complexity, shop-floor operators need to be properly supported in order to perform their important work. The shop-floor operators in this future complex manufacturing industry, the Operator 4.0, need to be supported with the implementation of new cognitive automation solutions. These automation solutions, together with the innovativeness of new processes and organizations will increase the competitiveness of the manufacturing industry. This paper discusses three different aspects of production innovation in the context of the needs and preferences of information for Operator 4.0. Conclusively, product innovations can be applied in the manufacturing processes, and thus becoming process innovations, but the implementation of such innovations require organizational innovations.
\end{abstract}

Keywords. Production innovation, human-centred production, information dissemination, Industry 4.0, Operator 4.0.

\section{Introduction}

As the manufacturing industry moves from mass-production of high-volume products towards mass-customization with high-variant products [1], complexity in manufacturing is increasing [2]. This ever-growing complexity will continue to increase as many companies in the manufacturing industry turn to personalized production as their strategy in order to gain a competitive advantage, for example, the concept of lot-sizeof-one where products become engineered-to-order [3]. To manage such complexity, more challenges will be put on the people working on the shop-floors in the future [4].

In this context, it is important for companies to ensure that their employees have relevant data, information and knowledge necessary to make well-founded decisions [5]. Due to new possibilities with Industry 4.0 and its enabling technologies, the amount of available data, information and knowledge increases rapidly, but the insights into how to utilize it to its full potential are still lacking [6]. In order for Operator 4.0 to be able to

${ }^{1}$ Corresponding Author. dan.li@chalmers.se 
manage the influx of data, information and knowledge, its dissemination needs to be effective [7].

New production innovations need to be developed for the effective dissemination of data, information and knowledge that supports Operator 4.0 [8]. Such innovations in production will enable companies to face the challenges of increased complexity and retain a competitive advantage [9].

In essence, this paper focuses on the intersections of three areas, visualized in Figure 1; production innovation, the effective dissemination of information, and Operator 4.0. These three research interests are explored in a chapter each, followed by a discussion on the intersections and conclusion.

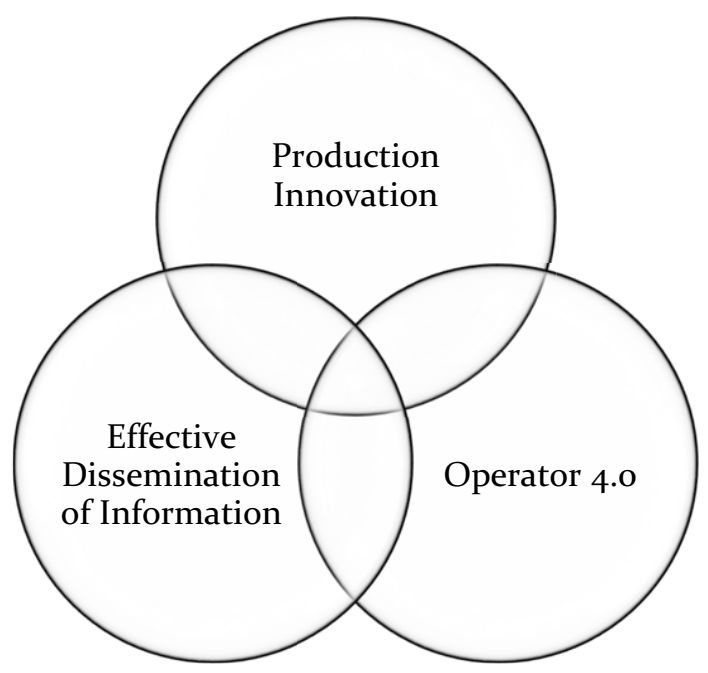

Figure 1. Venn diagram of the three research interests.

\section{Production Innovation}

A conventional approach to conceptualize innovation is emphasizing product innovations [10]. However, the concept of innovation is broader and encompasses a wider range of disciplines [11]. In general, OECD/European Communities [12] has defined innovation as "the implementation of a new or significantly improved product (good or service), or process, a new marketing method, or a new organisational method in business practices, workplace organisation or external relations", and subsequently identified four types of innovation found within this definition:

- Product innovation: A good or service that is new or significantly improved. This includes significant improvements in technical specifications, components and materials, software in the product, user-friendliness or other functional characteristics.

- Process innovation: A new or significantly improved production or delivery method. This includes significant changes in techniques, equipment and/or software. 
- Marketing innovation: A new marketing method involving significant changes in product design or packaging, product placement, product promotion or pricing.

- Organizational innovation: A new organizational method in business practices, workplace organization or external relations.

All these four types of innovation are covered within the viewpoint that, despite coming in many forms, innovations are strongly linked to engineering and industrialization [10]. In this industrialization context, marketing innovations represent the increased demand for the product, which also affects the product itself [12]. However, for shop-floor operators, the other three innovation types become more prevalent [13]. Managing creativity that contributes to product, process, or organizational innovations is not easy - the tension between people and ideas needs to be both positive and productive [14].

Narrowing from innovation in general to production innovation in particular, Larsson [15] defines it as "a process of change, where ideas are transformed into new processes, technologies, tools and/or work methods within a production system to create value for the organization and its stakeholders".

Often the focus point, development of product innovations are based on customer demands [13]. However, the manufacturing industry itself can also be customers in need of product innovations to improve aspects of the manufacturing process [16]. Traditionally, development of process innovations tends to focus on problem-solving that facilitates improved efficiency of manufacturing the products [13]. As customers, product innovations can be applied as process innovations to support new manufacturing demands [17].

If production innovation in the manufacturing industry is observed through the lenses of shop-floor operators, product innovations can be both the manufactured good and as enablers for process innovations, which in turn requires consideration of organizational innovations. Such organizational innovations that support shop-floor operators cognitively, improve their level of performance [18], thus contributing to quality-related value-creation [19].

\section{Effective Dissemination of Information}

Many existing frameworks for the dissemination of data, information and knowledge within organizations don't have a clear focus to capture the many advantages provided by the recent development of technologies that enable Industry 4.0 [20]. Examples of such enabling technologies, for which production-related data, information and knowledge can both be created and subsequently disseminated, include:

- Cyber-Physical Systems [21,22,23,24]

- $\quad$ Big Data $[24,25]$

- $\quad$ Cloud Computing [23,24,25]

- Internet of Things $[22,23,24]$

Intrinsically, data doesn't carry value on its own until it has been endowed with purpose or relevance and thus transformed to information, for example as simple as adding a unit to a measurement [26]. On the other hand, knowledge requires a higher level of understanding [27], which is dependent on the commitment and beliefs of 
individual humans [28]. Information, placed in-between data and knowledge [29], is similar to both, but neither data or knowledge are similar to each other [30]. This information represents the important data or codified knowledge that can be shared to support people at work.

Examples of information that is conceptually closer to data could be performance measurements relating to safety, quality, delivery, or cost, which are based on data measurements [31]. Examples of information that is conceptually closer to knowledge could be assembly instructions, which are based on product knowledge [32]. Whether it is measurements or instructions, operators benefit from both being effectively disseminated [7].

Dissemination of information is generally characterized by its location, rules and norms [33]. Development of enabling technologies has facilitated such communication to transcend traditional face-to-face interaction in the same time - same place context, contributing towards flexibility when it comes to both time and place for the actors partaking in the activity when information is disseminated [34,35]. As shown in Figure 2 , this flexibility entails that information can be disseminated with the source and recipient actors communicating at the same or different times, as well as at the same of different places [36].

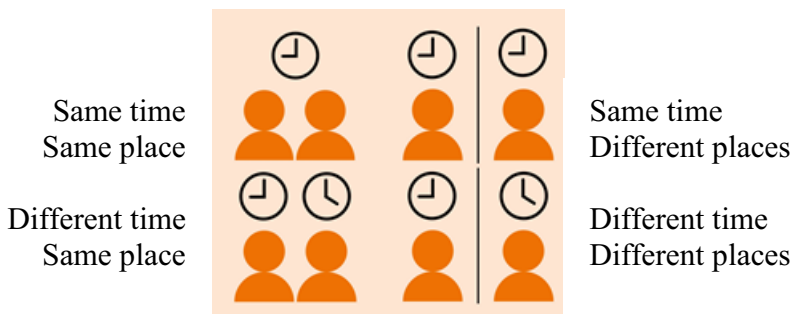

Figure 2. Flexibility in the dissemination of information with regards to time and place for the actors [36].

\section{Operator 4.0}

While not a fully consolidated term [22], the incoming paradigm of Industry 4.0 [9] has attracted interest from both practitioners and researchers [37]. In this context, the manufacturing industry is proactively [38] undergoing a technology-driven [21] paradigm shift towards increased digitisation, automation, and communication [39].

In this complex Industry 4.0, human operators remain as invaluable resources [5] because of capabilities such as coordination and problem-solving [40], and decisionmaking [41]. Romero et al. [8] propose eight concepts for how Operator 4.0 can become smarter operators:

- Operator + Exoskeleton

- Operator + Augmented Reality

- Operator + Virtual Reality

- Operator + Wearable Tracker

- Operator + Intelligent Personal Assistant

- Operator + Collaborative Robot

- Operator + Social Networks

- Operator + Big Data Analytics
$=$ Super-Strength Operator

$=$ Augmented Operator

$=$ Virtual Operator

$=$ Healthy Operator

$=$ Smarter Operator

$=$ Collaborative Operator

$=$ Social Operator

$=$ Analytical Operator 
As the future of industrial work is changing $[42,43]$, these skilled human operators of the future can and should be aided cognitively in order to create socially sustainable workplaces [44] by simplifying and enabling dissemination of information that supports humans at work [45]. Yet, it remains difficult for many companies to implement digital technologies related to Industry 4.0 for such purposes $[46,47,48]$. Hence, it is necessary to consider future challenges affecting the cognitive workload of Operator 4.0, such as:

- technological solutions, virtual models and augmented reality $[45,49]$

- managing data, how it is shared and visualized $[45,49]$

- qualification, employment and leadership [45]

- IT proficiency, learning and training for operators [45,49]

- new forms of human-machine interactions [49]

- technology forecasting [49]

\section{Discussion}

Moving away from previous frameworks for the dissemination of information within organizations, newer frameworks have the benefit to include concepts related to Industry 4.0 [20]. New innovations in production systems have the opportunity to enable effective dissemination of information to better support the work of Operator 4.0 by including competitive, as well as cognitive, advantages within the Industry 4.0 paradigm [43].

\subsection{Production Innovation for Operator 4.0}

To innovate with the shop-floor operators as the intended target beneficiaries can help create more sustainable workplaces in Industry 4.0. Changing how people work on shopfloors affect techniques and equipment that are required to perform the work tasks. The development efforts for improving work tasks are important process innovations that improve the overall performance of modern production systems.

Implementation of new technologies and new work methods, in the shape of product and process innovations, will put new demands on Operator 4.0. Furthermore, organizational innovations such as game-based learning or serious games used for lifelong learning will be vital for Operator 4.0 in order to remain competitive throughout the entire career. For Operator 4.0, new product innovations may lead to an increased need for new concepts regarding the work environment. This could, in turn, create a sense of urgency for both process and organizational innovations for manufacturing companies.

\subsection{Production Innovation and Effective Dissemination of Information}

Production innovations, foremost process and organizational innovation such as digital shadows, digital and effective instructions and faster feedback loops to the operators, can support the effective dissemination of information in various ways. New off-the-shelf Information and Communication Technologies (ICT) have the possibility to support the faster transfer of relevant and useful information between different people. ICT and similar technologies that already are available on the consumer market are important product innovations that can be implemented in modern production systems. Implementation of such immediate innovations is dictated by the type of information content and its necessity for the operators. 


\subsection{Effective Dissemination of Information for Operator 4.0}

Dissemination of information can support the everyday work of shop-floor operators if the shared information is relevant and useful [7]. However, despite the advantages of product innovations and process innovations, shop-floor operators need to be involved and engaged in a consensus design of the important organizational innovations that need to reflect how people want to work in modern production systems for the dissemination to become effective [20].

Out of the eight concepts for making Operator 4.0 smarter [8], four proposals affect how information is disseminated and presented to the operator when considering the future challenges affecting the cognitive workload [45,49], namely using the product innovations of augmented reality, virtual reality, intelligent personal assistants, and social networks. These four product innovations enable new approaches for how information can cognitively support Operator 4.0 but also create a demand for new process and organizational innovations.

\subsection{Production Innovation and Effective Dissemination of Information for Operator 4.0}

To summarize, in section 1, four types of innovation were presented [12], out of which three types are more prevalent for Operator 4.0 and linked to production innovation. Subsequently, in section 4.1, the implications of these three types of innovation were discussed:

- Product innovation

- Process innovation

- Organizational innovation

In section 2, the effective dissemination of information was introduced, and for Operator 4.0 two situations of information dissemination were exemplified; meetings and work instructions. More generally speaking, such information dissemination can occur with time-place flexibility, with implications of these discussed in section 4.2:

- Same time - same place

- Same time - different places

- Different time - same place

- Different time - different places

In section 3, eight concepts for Operator 4.0 were introduced [8] that were narrowed down to four concepts that directly impacting how information is disseminated for Operator 4.0 in section 4.3:

- Operator + Augmented Reality

- Operator + Virtual Reality

- Operator + Intelligent Personal

- Operator + Social Networks
$=$ Augmented Operator

$=$ Virtual Operator

$=$ Smarter Operator

$=$ Social Operator

These three types of innovation, information dissemination and Operator 4.0 are summarized in Table 1, with additional examples of situations in the three other timeplace flexibility contexts that transcend the same time-same place norm. 
Table 1. Types of innovation and Operator 4.0

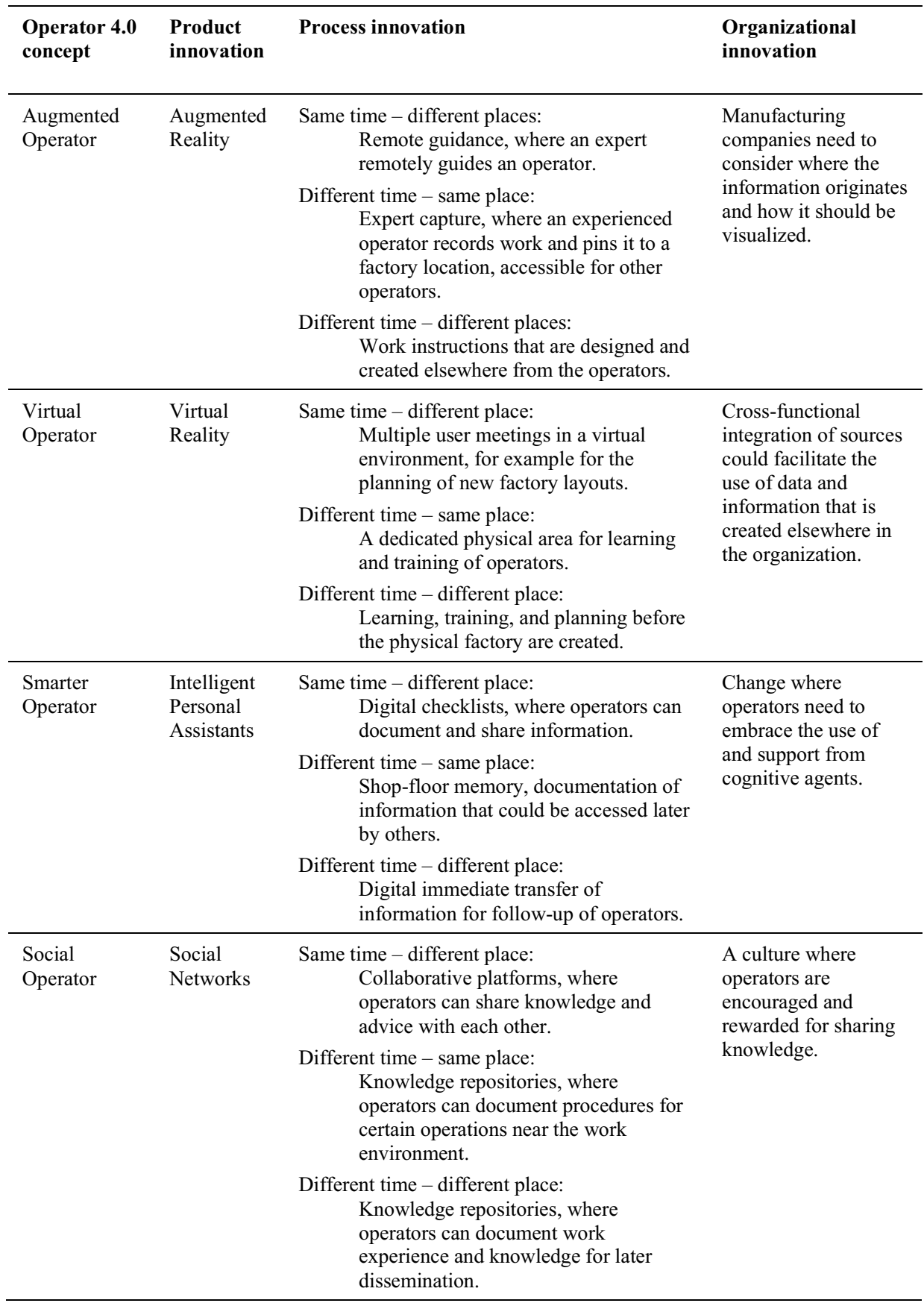

In Table 1, some examples of future operators are presented, with possible scenarios where data, information, and knowledge could be disseminated. While same time - same place communication could benefit from new innovations, new product innovations 
create new possibilities for how information could be disseminated in the three other time-place flexibilities, as exemplified in Table 1, process innovation. These different situations lead to the necessity of new approaches for how manufacturing companies design its work environment and processes, as exemplified in Table 1 - organizational innovations.

\subsection{Future Research}

Research and practice concerning production innovation, as insights into product innovation, process innovation, and organizational innovation, grants knowledge about possibilities for how to more effectively support Operator 4.0.

Concerning dissemination of information, there is a need for new organizational innovations to support the already emerging process and product innovations, i.e. Industry 4.0 and its enabling technologies.

While this paper has discussed that there are opportunities for developing organizational innovations to more effectively disseminate information for Operator 4.0, a question for future research remains: How should such an organizational innovation Organization 4.0 - be designed to support the effective dissemination of information for Operator 4.0 ?

\section{Conclusion}

To use innovation as a mechanism to enable effective dissemination of information in the manufacturing industry to provide better cognitive support in the everyday work of shop-floor operators, three types of innovation needs to be considered, and subsequently, these three types of innovation are strongly linked to production innovation in this context.

While product innovations have the capabilities to transform how this effective dissemination of information can be conducted, its actual implementation requires process innovations for them to be relevant and useful. However, organizational innovations are necessary, since, in the end, it is all about how people want to work.

In conclusion, to support the effective dissemination of information for Operator 4.0 in modern production systems, product innovations can be implemented as process innovations, but organizational innovations are required for avoiding disuse or misuse of the production innovations.

\section{Acknowledgements}

The research has been carried out within the research projects Global Assembly Instruction Strategies 2 and Demonstrating and Testing Smart Digitalisation for Sustainable Human-Centred Automation in Production, both funded by Vinnova, the Swedish Governmental Agency for Innovation Systems. This support is gratefully acknowledged.

This paper is influenced by the knowledge about innovation from Professor Anna Öhrwall Rönnbäck of Luleå University of Technology and Associate Professor Kerstin Johansen of Linköping University. Their inspiration is gratefully acknowledged. 


\section{References}

[1] F. Jovane, Y. Koren and C.R. Boër, Present and Future of Flexible Automation: Towards New Paradigms, CIRP Annals, vol. 52, 2003, pp. 543-560.

[2] W. ElMaraghy, H. ElMaraghy, T. Tomiyama and L. Monostori, Complexity in engineering design and manufacturing, CIRP Annals, vol. 61, 2012, pp. 793-814.

[3] T. Stock and G. Seliger, Opportunities of Sustainable Manufacturing in Industry 4.0, Procedia CIRP, vol. 40, 2016, pp. 536-541.

[4] S. Mattsson, A. Fast-Berglund, D. Li and P. Thorvald, Forming a cognitive automation strategy for Operator 4.0 in complex assembly, Computers \& Industrial Engineering, vol. 139, 2020.

[5] C. Toro, I. Barandiaran and J. Posada, A Perspective on Knowledge Based and Intelligent Systems Implementation in Industrie 4.0, Procedia Computer Science, vol. 60, 2015, pp. 362-370.

[6] E. Kaasinen, F. Schmalfuß, C. Özturk, S. Aromaa, M. Boubekeur, J. Heilala, P. Heikkilä, T. Kuula, M. Liinasuo, S. Mach, R. Mehta, E. Petäjä and T. Walter, Empowering and engaging industrial workers with Operator 4.0 solutions, Computers \& Industrial Engineering, vol. 139, 2020.

[7] D. Li, D. Paulin, Å. Fast-Berglund, P. Gullander and L.-O. Bligård, Supporting Individual Needs for Intra-Organizational Knowledge Sharing Activities in Pre-Industry 4.0 SMEs, In: 15th International Conference on Intellectual Capital, Knowledge Management \& Organisational Learning, Cape Town, 2018, pp. 160-170.

[8] D. Romero, J. Stahre, T. Wuest, O. Noran, P. Bernus, Å. Fast-Berglund and D. Gorecky, Towards an Operator 4.0 Typology: A Human-Centric Perspective on the Fourth Industrial Revolution Technologies, In: 46th International Conference on Computers \& Industrial Engineering, Tianjin, 2016.

[9] X. Yao and Y. Lin, Emerging manufacturing paradigm shifts for the incoming industrial revolution, The International Journal of Advanced Manufacturing Technology, vol. 85, 2016, pp. 1665-1676.

[10] K. Sedig, Swedish Innovations, 3rd Revised Edition, The Swedish Institute, Stockholm, 2006.

[11] OECD/Eurostat, Oslo Manual 2018: Guidelines for Collecting, Reporting and Using Data on Innovation, 4th Edition, OECD Publishing, Paris, 2018.

[12] OECD/European Communities, Oslo Manual: Guidelines for Collecting and Interpreting Innovation Data, 3rd Edition, OECD Publishing, Paris, 2005.

[13] H. Boer and W.E. During, Innovation, what innovation? A comparison between product, process, and organizational innovation, International Journal of Technology Management, vol. 22, 2001, pp. 83-107.

[14] S.G. Isaksen and G. Ekvall, Managing for Innovation: The Two Faces of Tension in Creative Climates, Creativity and Innovation Management, vol. 19, 2010, pp. 73-88.

[15] L. Larsson, Characteristics of Production Innovation, Luleå University of Technology, Luleå, 2017.

[16] J.D. Linton, De-babelizing the language of innovation, Technovation, vol. 29, 2009, pp. 729-737.

[17] M.P. Taylor, P. Boxall, J.J.J. Chen, X. Xu, A. Liew and A. Adeniji, Operator 4.0 or Maker 1.0? Exploring the implications of Industrie 4.0 for innovation, safety and quality of work in small economies and enterprises, Computers \& Industrial Engineering, vol. 139, 2020.

[18] D. Li, S. Mattsson, O. Salunkhe, Å. Fast-Berglund, A. Skoogh and J. Broberg, Effects of Information Content in Work Instructions for Operator Performance, Procedia Manufacturing, vol. 25, 2018, pp. 628635.

[19] L. Larsson, J. Stahre, C. Warrol and A. Öhrwall Rönnbäck, An Assessment Model for Production Innovation: The Program Production2030, Procedia Manufacturing, vol. 25, 2018, pp. 134-141.

[20] D. Li, Å. Fast-Berglund and D. Paulin, Current and future Industry 4.0 capabilities for information and knowledge sharing, The International Journal of Advanced Manufacturing Technology, vol. 105, 2019, pp. 3951-3963.

[21] H. Lasi, P. Fettke, H.-G. Kemper, T. Feld and M. Hoffman, Industry 4.0, Business \& Information Systems Engineering, vol. 6, 2014, pp. 239-242.

[22] A.C. Pereira and F. Romero, A review of the meanings and the implications of the Industry 4.0 concept, Procedia Manufacturing, vol. 13, 2017, pp. 1206-1214.

[23] L.D. Xu, E.L. Xu and L. Li, Industry 4.0: state of the art and future trends, International Journal of Production Research, vol. 56, 2018, pp. 2941-2962.

[24] V. Alcácer and V. Cruz-Machado, Scanning the Industry 4.0: A Literature Review on Technologies for Manufacturing Systems, Engineering Science and Technology, an International Journal, vol. 22, 2019, pp. 899-919.

[25] L.S. Dalenogare, G.B. Benitez, N.F. Ayala and A.G. Frank, The expected contribution of Industry 4.0 technologies for industrial performance, International Journal of Production Economics, vol. 204, 2018, pp. 383-394.

[26] T.H. Davenport and L. Prusak, Working Knowledge: How Organizations Manage What They Know, Harvard Business Press, Boston, 1998.

[27] P.F. Drucker, The Coming of the New Organization, Harvard Business Review, vol. 66, 1988, pp. 45-53. 
[28] I. Nonaka, A Dynamic Theory of Organizational Knowledge Creation, Organization Science, vol. 5, 1994, pp. 14-37.

[29] R.L. Ackoff, From Data to Wisdom, Journal of Applied Systems Analysis, vol. 16, 1989, pp. 3-9.

[30] J. Rowley, Towards a Framework for Information Management, International Journal of Information Management, vol. 18, 1998, pp. 359-369.

[31] A. Landström, P. Almström, M. Winroth, C. Andersson, C. Windmark, S. Shahbazi, M. Wiktorsson, M. Kurdve, M. Zackrisson, M. Ericson Öberg and A. Myrelid, Present state analysis of business performance measurement systems in large manufacturing companies, In: Performance Measurement Association Conference, Edinburgh, 2016.

[32] P.E.C. Johansson, L. Malmsköld, Å. Fast-Berglund and L. Moestam, Enhancing Future Assembly Information Systems - Putting Theory into Practice, Procedia Manufacturing, vol. 17, 2018, pp. 491498.

[33] R.E. Purser, W.A. Pasmore and R.V. Tenkasi, The influence of deliberation in learning in new product development teams, Journal of Engineering and Technology Management, vol. 9, 1992, pp. 1-28.

[34] R.M. Baecker, Readings in Groupware and Computer-Supported Cooperative Work: Assisting HumanHuman Collaboration. Morgan Kaufmann Publishers, San Mateo, 1992.

[35] J. Grudin, Computer-Supported Cooperative Work: History and Focus, Computer, vol. 27, 1994, pp. 1926.

[36] D. Li, Effective Sharing of Information and Knowledge in Production Systems, Chalmers University of Technology, Gothenburg, 2019.

[37] Y. Liao, F. Deschamps, E.d.F.R. Loures and L.F.P. Ramos, Past, present and future of Industry 4.0-a systematic literature review and research agenda proposal, International Journal of Production Research, vol. 55, 2017, pp. 3609-3629.

[38] F. Almada-Lobo, The Industry 4.0 revolution and the future of Manufacturing Execution Systems (MES), Journal of Innovation Management, vol. 3, 2015, pp. 16-21.

[39] T.D. Oesterreich and F. Teuteberg, Understanding the implications of digitisation and automation in the context of Industry 4.0, Computers in Industry, vol. 83, 2016, pp. 121-139.

[40] M. Brettel, N. Friederichsen, M. Keller and M. Rosenberg, How Virtualization, Decentralization and Network Building Change the Manufacturing Landscape: An Industry 4.0 Perspective, International Journal of Information and Communication Engineering, vol. 8, 2014, pp. 37-44.

[41] J.A. Stankovic, Research Directions for the Internet of Things, IEEE Internet of Things Journal, vol. 1, 2014, pp. 1-7.

[42] S. Waschull, J.A.C. Bokhorst, E. Molleman and J.C. Wortmann, Work design in future industrial production: Transforming towards cyber-physical systems, Computers \& Industrial Engineering, vol. $139,2020$.

[43] M. Bortolini, E. Ferrari, M. Gamberi, F. Pilati and M. Faccio, Assembly system design in the Industry 4.0 era: a general framework, IFAC-PapersOnLine, vol. 50, 2017, pp. 5700-5705.

[44] D. Romero, J. Stahre and M. Taisch, The Operator 4.0: Towards socially sustainable factories of the future, Computers \& Industrial Engineering, vol. 139, 2020.

[45] D. Li, A. Landström, Å. Fast-Berglund and P. Almström, Human-Centred Dissemination of Data, Information and Knowledge in Industry 4.0, Procedia CIRP, vol. 84, 2019, pp. 380-386.

[46] D. Bittighofer, M. Dust, A. Irslinger, M. Liebich and L. Martin, State of Industry 4.0 across German Companies: A pilot study, In: IEEE International Conference on Engineering, Technology and Innovation, Stuttgart, 2018.

[47] Z. Chengula, M.A. Rubio Morato, T. Thurner, Y. Wiedensohler and L. Martin, State of Industry 4.0 across six French companies: A pilot study, In: IEEE International Conference on Engineering, Technology and Innovation, Stuttgart, 2018.

[48] J. Stentoft, K. Wickstrøm Jensen, K. Philipsen and A. Haug, Drivers and Barriers for Industry 4.0 Readiness and Practice: A SME Perspective with Empirical Evidence, In: 52nd Hawaii International Conference on System Sciences, Maui, 2019, pp. 5155-5164.

[49] B.A. Kadir, O. Broberg and C.S.d. Conceição, Current research and future perspectives on human factors and ergonomics in Industry 4.0, Computers \& Industrial Engineering, vol. 137, 2019. 